\title{
PRODUCCIÓN, PRECIOS E INTEGRACIÓN DE LOS MERCADOS REGIONALES \\ DE GRANO EN LA ESPAÑA PREINDUSTRIAL ${ }^{1}$
}

\author{
DAVID S. REHER
}

Universidad Complutense de Madrid

\section{RESUMEN}

Este trabajo aborda la integración de los distintos mercados regionales de grano en España durante el Antiguo Régimen. Haciendo uso de series de precios y de producción de diversa procedencia, el autor emplea técnicas de estimación relativamente sencillas, desde correlaciones y desviaciones típicas de series sin tendencia hasta modelos de retardos distribuidos. Estas técnicas revelan la existencia de una covariación entre los precios de granos en distintos mercados regionales, así como la existencia de efectos simultáneos y retardados de la producción de granos sobre el precio de los mismos en mercados locales y bastante más lejanos. El autor concluye que existía una integración modesta pero en aumento de los distintos mercados en la Península, sobre todo durante el siglo xvII, y que las instituciones eran capaces de amortiguar en parte los efectos de una cosecha fallida. El trabajo concluye apuntando el calendario posible de la progresiva integración de los mercados de grano ocurrida a lo largo de buena parte del siglo xix en España.

$N$. de E.: Fecha de recepción del artículo en la Revista de Historía Económica: marzo de 2000 .

Fecha de aprobación por el Consejo de Redacción: noviembre de 2001.

1 Versiones preliminares de este trabajo se han presentado en los seminarios de Historia Económica de las facultades de Ciencias Económicas y Empresariales de la Universidad Complutense de Madrid y de la Universitat de Barcelona. El autor quiere agradecer a los participantes en dichos seminarios así como, y de modo especial, a Enrique Llopis, José Antonio Ortega Osona, Miguel Jerez, Larry Epstein, Juan Díez Nicolás, Gaspar Feliú, Blanca Sánchez Alonso, Dudley Baines, así como a los evaluadores externos de la Revista de Historia Económica por sus valiosas críticas y sugerencias. Quisiera también reconocer su deuda con Esmeralda Ballesteros Doncel, Vicente Pérez Moreda y Gaspar Feliú por haberle facilitado datos suyos inéditos. 


\begin{abstract}
The present paper deals with regional grain market integration in Spain during the Old Regime. Using mostly published price and production series, the author employs straightforward statistical techniques, ranging from correlations and standard deviations of detrended series to distributed lag models. These techniques show the existence of a clear covariation in the price of grain on different regional markets, as well as both simultaneous and delayed effects of grain production on prices both locally and at considerably greater distances. The author concludes that regional grain markets on the peninsula were modestly but increasingly integrated over the period, especially during the eighteenth century, and that existing institutions were a partial buffer for the immediate effects of harvest failures. The paper concludes by suggesting the potential timing for the progressive intergration of grain markets taking place throughout much of the nineteenth century in Spain.
\end{abstract}

\title{
INTRODUCCIÓN
}

A lo largo del Antiguo Régimen, el nivel alimenticio de la población, y con ello su verdadero nivel de vida, dependía estrechamente de la disponibilidad de alimentos y, en concreto, de los alimentos clave para su sustento, como, por ejemplo, los cereales y especialmente el trigo. Prueba de ello es el hecho de que los presupuestos de gasto existentes para cualquier país europeo antes del siglo actual revelan que la gran mayoría de los gastos corrientes familiares se dedicaban a la alimentación (normalmente entre 60 y 75 por 100) y, de ellos, una buena parte se utilizaba para la compra de pan y de otros cereales ${ }^{2}$. Si consideramos que estos presupuestos reflejan el consumo familiar, cabe decir que entre un tercio y la mitad de los ingresos se dedicaban a la compra de trigo. Incluso en familias productoras más que compradoras de alimentos, no sería exagerado afirmar que la gran mayoría del «esfuerzo familiar» se invertía en la consecución del alimento necesario para sobrevivir. Es evidente que las sociedades del pasado eran, por su misma naturaleza, heterogéneas y la distribución de gastos en familias de cierto posición social, o las de ubicación ecológica o actividad económica ventajosas, no se dedicaría tan abrumadoramente al logro del alimento suficiente para sobrevivir. Pero también es cierto

2 Para estimaciones de una cesta de la compra para poblaciones del Antiguo Régimen, véase, por ejemplo, Reher y Ballesteros (1993a, pp. 103-106), Phelps Brown y Hopkins (1956, p. 297; 1957; 1959); Martín Aceña (1992). Para los siglos xIX y la primera parte del $\mathrm{xx}$, véase Reher y Ballesteros (1993a, pp. 111-118; 1993b), Ballesteros (1997, 1999). 
que, para la gran mayoría de la población, sí que era el caso. Aunque el estudio de los grupos privilegiados al respecto será siempre instructivo, no minimiza la importancia del hecho de que el bienestar de la mayoría de la población dependía estrechamente de la disponibilidad de alimentos.

Por otra parte, es preciso tener presente que la demanda de alimentos, y sobre todo la demanda de trigo, tendía a ser inelástica, probablemente bastante más que ningún otro producto dentro de una hipotética «cesta de la compra». Por ello, cabe decir que las fluctuaciones en los precios de los alimentos, y en especial en el precio del trigo, constituían uno de los determinantes centrales en las oscilaciones en el corto y el medio plazo de los niveles de vida de la población. Habitualmente se considera que estas fluctuaciones en una región o comarca determinada respondían básicamente a las fluctuaciones en las cosechas. Dentro de una agricultura en la que las tierras de cultivo en regadío eran mínimas, donde las tecnologías agrícolas eran más bien rudimentarias y la climatología podía llegar a sufrir bruscos cambios de un año a otro, las cosechas eran necesariamente muy inestables. En ausencia de tecnologías sofisticadas de producción y de almacenamiento de granos, y antes de una verdadera integración de los mercados, la única defensa contra la volatilidad de los precios y de la disponibilidad de alimentos en la España moderna sería de indole institucional. Sin embargo, habitualmente se ha considerado que estos recursos -que abarcaban desde los pósitos y la tasa de granos hasta el papel de la Iglesia, bien como prestamista, o bien como fuente de limosna-, a pesar de sus buenas intenciones, carecían de eficacia ${ }^{3}$.

En cuanto a una verdadera integración de los mercados regionales y locales en la Península, donde la abundancia de productos de una región pudiese servir para paliar su escasez en otra, normalmente se considera que no llegó a ser una realidad antes de la construcción de una red viaria nacional realmente eficaz; es decir, no antes de, al menos, la última parte del siglo $\mathrm{XIX}^{4}$. En épocas anteriores, la población no tendría más remedio que someterse a los caprichos de las cosechas y de los precios, con un apoyo institucional ineficaz y una capacidad para prevenir el riesgo muy limitado. Sólo escaparian a esta dinámica aquellas regiones costeras en condiciones de acceder al trigo por medio del comercio internacional de granos. Si bien un año medianamente malo se podía sortear, no sin difi-

' Véase, por ejemplo, Domínguez Ortiz (1973, pp. 22-35; 1976, pp. 408-428); Reher (1990, pp. 155-163); Anes Alvarez (1974, pp. 219-224); Castro (1987, pp. 69-86); Marcos Martín (2000, pp. 122-126).

+ Para más sobre este tema, véase, por ejemplo, Anes y Álvarez (1969, pp. 45-70). 
cultad, cuando se juntaban más de uno la situación podía llegar a ser dramática. Las fuentes de la época están llenas de testimonios de personas que sufrían una extremada penuria en tiempos de carestía e incluso de personas que morian de hambre. Así, las crisis de subsistencias serían un aspecto estructural en la vida de las poblaciones del Antiguo Régimen.

He aquí, en líneas generales, la forma habitual de comprender la relación entre cosechas, precios y nivel de vida en las poblaciones del Antiguo Régimen ${ }^{5}$. Muy pocos historiadores económicos disputarían su validez salvo en cuestiones de detalle. Esta interpretación adolece, sin embargo, de dos puntos endebles que formarán el eje de este escrito. Por un lado, se pueden disputar algunas de sus premisas básicas y, por otro, buena parte de ellas descansan sobre estudios poco rigurosos e incluso impresionistas de la realidad histórica. En cuanto a este segundo punto, a pesar de una cierta abundancia de series de precios ${ }^{6}$, existen pocos estudios empíricos sistemáticos que aborden la integración regional de las series de precios, las relaciones entre producción y precios, o la incidencia de factores institucionales en estas cuestiones. Los estudios más ambiciosos y rigurosos suelen centrarse en la generación de series de salarios reales y en aquellos trabajos que han intentado abordar las implicaciones para los comportamientos demográficos de las fluctuaciones anuales en los precios ${ }^{\text {? }}$. Pero ello parece insuficiente si consideramos el calado histórico de esta cuestión.

Por otro lado, cabría afirmar que las fluctuaciones en los precios únicamente tienen sentido para aquellos sectores de la población que han

5 Para el tema de los niveles de vida en el mundo rural, la bibliografía es amplia. Como botón de muestra cabe citar Torras (1997) o Martínez Carrión (1997).

"Para el Antiguo Régimen, varias de las series existentes se irán citando a lo largo de este trabajo. Basta aquí recordar la obra monumental de Earl Hamilton [1934 (1975) y 1947 (1988)], punto de arranque para cualquier estudio de precios en España. Para diferentes análisis de series de precios, véase también, por ejemplo, Martín Aceña (1989), Escrivá y Llopis (1987) y Reher y Ballesteros (1993a). Para el siglo XIX, es de cita obligada la serie de trabajos de Nicolás Sánchez-Albornoz (1963, 1974, 1975a, 1975b), así como el que realizó este autor junto con Daniel Peña (Peña y Sánchez-Albornoz, 1983). Véase también, entre otras, las series recientes de Ballesteros Doncel (1997, 1999), Martínez Vara (1997), Martínez Vara y Guigó (1999), Serrano Garcia (1999), Pérez Sánchez (1996), Barquín Gil (1997, 1999), así como la serie referida de Reher y Ballesteros (1993a). Para la Baja Edad Media en Aragón, véase, por ejemplo, Zulaica Palacios (1994).

7 A modo de excepción, son de obligada cita los trabajos de Escrivá y Llopis (1987), Sánchez-Albornoz (1963, 1975a, 1975b) y de Peña y Sánchez-Albornoz (1983). Cabe citar también aquellos estudios que relacionan las fluctuaciones en los precios con los cambios a corto plazo de las variables demográficas (fecundidad, mortalidad, nupcialidad). Véase, al respecto, Reher (1988) y Pérez Moreda (1988). Para una evaluación comparativa de las relaciones a medio y largo plazo entre salarios, precios y dinámicas demográficas en Castilla, Inglaterra y el norte de Italia, véase Reher y Ortega Osona (2000). En el terreno europeo existe una amplia bibliografía acerca de las fluctuaciones de precios y su relación con la producción. Como brevisimo botón de muestra cabe citar la obra reciente de Grenier 
de acudir a los mercados para conseguir su sustento. Esto mismo lo afirmó Robert Fogel en el seminario sobre Población y Economía que tuvo lugar en Japón en $1997^{8}$. En el transcurso de unos debates muy animados, afirmó que las series de precios eran muy importantes para comprender las fluctuaciones a corto y medio plazo en los niveles de vida de las poblaciones urbanas y de ciertos sectores de las poblaciones rurales, pero carecía de sentido utilizarlas para los mismos fines cuando se analizaba la población privilegiada o la población productora de alimentos. Estas últimas podían incluso terminar beneficiándose de las subidas de precios a la hora de vender sus excedentes a precios elevados. En nuestra opinión, esta afirmación, desde luego acertada en parte, ignora dos hechos fundamentales en la mayor parte de las sociedades del Antiguo Régimen. Por un lado, existen muy pocos grupos sociales que no tengan que acudir de una manera u otra al mercado para la compra de alimentos. Si bien algunas familias podrían vender ciertos productos en el mercado, tenían que acudir a él para otros. En este sentido, nunca estarían exentos del todo de los efectos nocivos de las épocas de carestía.

Más importante, sin embargo, es que los precios deben reflejar ante todo la dinámica de las cosechas. Si los precios son elevados, parecería indicar que las cosechas han sido pobres. En esos casos, también se verían afectados los productores de alimentos al disponer de menos excedentes, o carecer del todo de ellos, para vender en el mercado. Así, con excepción de los grandes propietarios de tierras, las épocas de precios elevados significarían recortes en los ingresos de la mayor parte de las economías familiares campesinas. A este argumento el profesor Fogel opuso el razonamiento de que los precios de alimentos respondían a un conjunto de factores, donde las instituciones, el comercio nacional e internacional y la producción desempeñaban papeles importantes. Implícita en su afirmación está la existencia de una integración más o menos importante de los mercados de alimentos, donde la producción local sólo ocuparía un papel secundario en las oscilaciones en los niveles de vida de la población.

(1996) (la tercera y cuarta parte), o el estudio ya clásíco de E. A. Wrigley (1987), en particular el capítulo dedicado a «Some reflections on corn yields and prices in pre-industrial economies» (pp. 92-130).

${ }^{8}$ Se trata de un seminario preparatorio para una Sesión «A» del Twelfth International Economic History Congress, organizado por el Comité de Demografía Histórica de la Unión Internacional para el Estudio Cientifico de la Población (IUSSP), que se celebró en Toyonaka City, cerca de Osaka (Japón), en septiembre del citado año. Para un resumen de los debates del seminario, véase Bengtsson et al. (1998). Para una selección de los trabajos presentados en el citado seminario, véase Bengtsson y Saito (2000). 
Así quedaron las interpretaciones discrepantes de esta cuestión y así quedó el intercambio, intenso y amistoso, que pudimos sostener con el ilustre historiador económico. Es a él a quien queremos dedicar este escrito que tiene por propósito comprobar la validez de los distintos puntos de vista expuestos en esa memorable sesión a la luz del funcionamiento de los mercados de grano en España durante la Edad Moderna. Haciendo uso de series de precios correspondientes a varias regiones de España, así como de la producción de cereales en tres de ellas, se analizará la volatilidad en los precios de cereales en los distintos mercados regionales, su evolución en el tiempo, los indicios de integración que presentan, y la relación entre la producción y los precios, tanto locales como en otras regiones. La variabilidad de los precios no es el único indicador de una hipotética integración de los mercados regionales, ya que tal proceso tendería a estimular asimismo una convergencia en los precios absolutos, siempre a igualdad de los precios de transporte, aspecto que queda fuera del alcance de este trabajo .

Nuestros resultados, a menudo robustos y elocuentes, permitirán comprobar la situación relativamente ventajosa de los mercados del litoral frente a los del interior, una reducción en la variabilidad de los precios a lo largo de la Edad Moderna - sobre todo visible durante buena parte del siglo XVIIL, una evidente relación entre producción y precios, indicios de una cierta integración de los mercados regionales que va en aumento a lo largo del período estudiado, y la importancia de factores institucionales, así como, posiblemente, de la capacidad de ahorro individual en la neutralización parcial de los avatares que presentaba la producción de cereales. También se podrá ver el verdadero despegue en la integración de los mercados durante buena parte del siglo XIX, una vez superado los desastrosos comienzos del siglo.

\section{DATOS Y MÉTODOS DE ANÁLISIS}

Existe un número no despreciable de series de precios de trigo para la España moderna. Para este estudio, partimos de las series regionales fundamentales contenidas en la gran obra de Earl Hamilton. Los precios que utiliza suelen basarse en libros de hospitales situados en más de una localidad. Por ello, pueden considerarse precios «regionales» en sentido

${ }^{4}$ Ello se debe a las distintas medidas y monedas utilizadas en las series existentes, así como a las alteraciones monetarias. 
aproximado. En los demás casos, las series utilizadas se basan en una sola localidad, normalmente - pero no siempre - una ciudad capital, por lo que cabe cuestionar, al menos en teoría, su representatividad para el conjunto de la región. Estos centros, entre los que se encuentran Sevilla, Pamplona, Barcelona, Valencia o Segovia, estaban en condiciones de comprar trigo en más de un mercado, a veces bastante distante, opción no siempre disponible para localidades menos importantes ${ }^{10}$. Cuando ha habido dos series distintas para una misma región, la serie final se ha logrado con números índice de ambas series con los años en común, siendo la media entre ambas ${ }^{11}$. Las series utilizadas y su origen se hallan recogidas en la Tabla 1 de este escrito.

En general, la calidad de estas series parece aceptable. El mayor problema proviene de los años en los que faltan datos. Cuando las lagunas han sido de sólo un año o dos, se han generado valores a partir de las tendencias de las otras series existentes o a partir de la suya propia; solución factible pero no perfecta ${ }^{12}$. Cuando las lagunas han sido mayores, se ha descartado la serie. El resultado no es ideal, pero las series resultantes parecen reunir una considerable verosimilitud. Otro problema no menor que hemos encontrado se refiere a los valores para Barcelona entre 1640 y 1652 , sobre todo los de 1651 y 1652 . En 1651 el precio del trigo se eleva casi 3 veces sobre su media de los años cercanos, y en 1652 la elevación es superior a los valores cercanos en casi 6 veces. Estas subidas de precio son producto de las alteraciones monetarias y de la guerra en Cataluña y, más concretamente, del estado de sitio en Barcelona vigente desde finales de 1651 hasta los primeros días de 1653. A fin de neutralizar

10 Esto mismo quedará de manifiesto con los resultados correspondientes a Sandoval en León, mercado mucho menos potente que otros de los utilizados aquí.

${ }^{1}$ Cabe aquí detallar el origen de la serie de precios de Segovia, que tiene varias procedencias diferentes. Entre 1614 y 1715 corresponde al Mercurial de Segovia y fue publicada por Anes y Le Flem (1965, pp. 54-55) y se encuentra expresada en años cosecha. Entre 1694 y 1792 proviene del mercado de la ciudad y se refiere al año civil por meses publicado en las Actas y Memorias de la Real Sociedad Económica de los Amigos del País de la Provincia de Segovia, tomo IV, Segovia, 1793, pp. 359-409. Entre 1793 y 1808 se refiere a medias anuales de precio del trigo en el mercado de la ciudad publicadas en el Correo Mercantil de España y sus Indias, 1792-1808. Pude tener acceso a la serie completa de Segovia, aún inédita, gracias a la amabilidad de Vicente Pérez Moreda. Para una explicación más completa de esta serie, véase Pérez Moreda (1988, pp. 114).

${ }^{12}$ Las lagunas encontradas en las series de precios ha sido las siguientes: Andalucía $(1583,1586,1590,1597,1631,1684)$; Castilla la Nueva $(1518,1540,1551-1553,1555$, $1558-1559,1581,1605,1626,1634,1686,1720,1722,1745,1747,1757,1775,1778$, 1784-1786); Valencia $(1587,1595,1787)$. 


\section{TABLA 1}

Series de precios y de producción utilizadas

\begin{tabular}{|c|c|c|c|}
\hline Región/lugar & Extensión & Tipo & Fuente \\
\hline \multicolumn{4}{|l|}{ Precio del trigo } \\
\hline Andalucia/Sevilla & $1582-1776$ & $\begin{array}{l}\text { Anual (año } \\
\text { cosecha) }\end{array}$ & $\begin{array}{l}\text { Hamilton }[1975 \text { (1934): } \\
\text { Apéndices IV, V] } \\
\text { (1582-1650, Andalucía); } \\
\text { Ponsot (1986, pp. 511-516) } \\
\text { (1640-1776, Sevilla) }\end{array}$ \\
\hline Barcelona & $1533-1808$ & $\begin{array}{l}\text { Anual (año } \\
\text { cosecha) }\end{array}$ & Feliú (1991, pp. 41-44) \\
\hline Castilla la Nueva & $1501-1800$ & Anual & $\begin{array}{l}\text { Hamilton [1975 (1934): } \\
\text { Apéndices IV, V; 1988 } \\
\text { (1947), pp. 273-290] }\end{array}$ \\
\hline León (Sandoval) & $1583-1810$ & Año cosecha & $\begin{array}{l}\text { Sebastián Amarilla (1992, } \\
\text { pp. 1252-1255) }\end{array}$ \\
\hline Segovia & $1615-1808$ & Año cosecha & Pérez Moreda (y otros) (s. f.). \\
\hline Navarra (Pamplona) & $1590-1841$ & Año cosecha & $\begin{array}{l}\text { Arizcun Cela (1989, } \\
\quad \text { pp.82-14) }\end{array}$ \\
\hline Valencia & $\begin{array}{l}1501-1650 \\
1725-1789\end{array}$ & Anual & $\begin{array}{l}\text { Hamilton [1975 (1934): } \\
\text { Apéndices IV, V] } \\
\text { (1501-1650); Palop Ramos } \\
\text { (1977, pp. 217-218) }\end{array}$ \\
\hline \multicolumn{4}{|c|}{ Producción de trigo [cereales] (diezmo) } \\
\hline $\begin{array}{l}\text { Castilla la Nueva (Ar- } \\
\text { zobispado de Tole- } \\
\text { do) }\end{array}$ & $1463-1800$ & $\begin{array}{l}\text { Anual } \\
\text { [cereales] }\end{array}$ & $\begin{array}{l}\text { López-Salazar Pérez y Martín } \\
\text { Galán (1981) (1463-1799); } \\
\text { Anes Álvarez (1970) (Alca- } \\
\text { lá de Henares) }\end{array}$ \\
\hline León (Sandoval) & $1569-1835$ & $\begin{array}{l}\text { Año cosecha } \\
\text { [trigo] }\end{array}$ & $\begin{array}{l}\text { Sebastián Amarilla (1992, } \\
\text { pp. 1081-1083) }\end{array}$ \\
\hline Segovia (Obispado) & $1570-1750$ & $\begin{array}{l}\text { Anual } \\
\text { [trigo] }\end{array}$ & $\begin{array}{l}\text { García Sanz (1999; Gráfico 2, } \\
\text { p. } 461 \text { ) }\end{array}$ \\
\hline
\end{tabular}


este problema, al menos en parte, hemos utilizado el precio del trigo expresado en plata durante esos años ${ }^{13}$. Aun así, estos dos años siguen siendo con diferencia los años de precios más elevados en la capital catalana para toda la serie utilizada y, además, siguen representando con diferencia una de las fluctuaciones más intensas de todas las series utilizadas.

Las series originales se hallan expresadas en distintas medidas y monedas, aunque, debido al hecho de que en este estudio se ha trabajado con series sin tendencia, esta diversidad no ha presentado problema alguno. Las series se expresan en valores anuales o en años cosecha (basados normalmente en la media de más de un valor mensual). Hemos decidido no intentar convertir los años civiles en años cosecha (o viceversa) a fin de no introducir sesgos innecesarios en los datos. Por lo tanto, es preciso tener cuidado a la hora de interpretar las relaciones entre series expresadas en años cosecha y años civiles. A todas las series se les ha quitado la tendencia al dividir el valor en el año " $x$ " por una media móvil de 11 términos centrada en " $x$ ". Este procedimiento, ya clásico en el análisis de series temporales, nos pareció más correcto que otros métodos de quitar la tendencia como, por ejemplo, primeras diferencias de logaritmos ${ }^{14}$. La media de cada una de las series es cercana a 1, y por lo tanto la desviación típica y otras estadísticas de las series en distintas regiones son fácilmente comparables.

También se han utilizado tres series de producción correspondiente a Castilla la Nueva, a la zona oriental del Reino de León y a Segovia. Hasta 1699, la serie castellana se refiere a la cantidad en especie del diezmo de cereales recogidas en los Libros de Vestuarios de la Catedral de Toledo. Estas series, que se encuentran en el admirable trabajo de Jerónimo López-Salazar y Manuel Martín Galán (1981), se hallan recogidas por los arciprestazgos del Arzobispado entre 1463 y 1699 y se expresan en fanegas de cereal. La serie regional es la media de los distintos arciprestazgos. La serie original se ha extendido hasta 1800 con los datos correspondientes

${ }^{13}$ Queremos agradecer a Gaspar Feliú por sus amables sugerencias sobre esta cuestión y por habernos facilitado los datos correspondientes a este período. Véase también, al respecto, Feliú (1991, pp. 23-56).

${ }^{1+}$ Las distintas maneras de quitar la tendencia, en realidad, no tratan de la misma forma a las series, siendo el método elegido la desviación frente a una tendencia relativamente corta en lugar del otro que prescinde de cualquier tendencia más allá del año anterior. En todo caso, a instancias de varios de nuestros colegas, se hicieron todos los análisis con series sin tendencia expresadas como primeras diferencias de logaritmos. Los resultados fueron prácticamente idénticos a los presentados aquí, salvo que los distintos coeficientes tendian a ser algo más bajos, pero con el mismo signo y grado de significación estadistica. 
a la participación de la Universidad de Alcalá en los diezmos correspondientes a los arciprestazgos de Alcalá ${ }^{15}$. Las lagunas en la serie de producción de Alcalá (1700-1800) se han cubierto con el valor medio entre el año anterior y el posterior ${ }^{16}$. También se ha utilizado una serie de producción de trigo correspondiente al Oriente leonés (Sandoval) en tierras no muy distantes de Tierra de Campos (Sebastián Amarilla, 1992). Por fin, hemos podido disponer del valor de los diezmos de trigo expresado en fanegas del Obispado de Segovia recogida por Ángel García Sanz. A todas estas series se les ha quitado la tendencia de la misma manera que las series de precios.

El aparato estadístico utilizado en este escrito será muy directo y sencillo, y apenas requiere explicación. Únicamente al analizar la relación entre producción y precios se emplearán modelos econométricos de retardos distribuidos para comprobar los efectos de las fluctuaciones en las cosechas (en un año determinado y en los años anteriores) sobre los precios (en el citado año) ${ }^{17}$. Este tipo de modelo se puede expresar con la siguiente ecuación:

$$
y_{t}=\alpha+\sum_{k=0}^{1,2} b_{k}(\mathrm{P})_{t-k}+\varepsilon_{t}
$$

donde $y_{t}$ recoge las fluctuaciones de precios sin tendencia para el año $t, \alpha$ es un constante, $b$ es el coeficiente del indicador de producción (P) en año $t, k=(0,1,2)$ es el número de observaciones retardadas de la variable independiente, y $\varepsilon$ es el término de error derivada de un proceso autoregresivo de segundo orden ${ }^{18}$. Debido a la forma de quitar la tendencia a las series, los coeficientes de regresión para cada retardo son elasticidades y se pueden interpretar como la importancia porcentual para la variable

${ }^{15}$ Los datos de Alcalá se han sacado directamente del Gráfico 11 del Apéndice del libro de Gonzalo Anes (1970).

16 Estos años son $1738,1741,1747,1772,1794$. La serie de Alcalá es a todas luces inferior a la de los arciprestazgos de Toledo, pero ha sido necesario utilizarla a fin de abarcar la totalidad del Antiguo Régimen.

1) Ronald Lee es el pionero de este método, utilizado habitualmente para evaluar las relaciones en el corto plazo entre fluctuaciones económicas (precios) y comportamiento demográfico. Véase, por ejemplo, Lee (1981), Galloway (1988). Para una evaluación general de este método, véase Bengtsson et al. (1998, pp. 99-115). Para la literatura económica, véase Greene (1997).

${ }^{1 *}$ Este último proceso resuelve el problema de autocorrelación. 
dependiente (precios) de un cambio de 100 por 100 en la variable independiente (producción).

\section{LOS MERCADOS REGIONALES DE GRANO EN ESPAÑA}

El comportamiento del precio del trigo era muy diferente en los mercados del interior de la Península que en los de la costa. En la costa, sin duda por su proximidad a las rutas del comercio internacional, la intensidad de las fluctuaciones en los precios del trigo era sensiblemente inferior que en la Meseta o en Andalucía. Ello se pone de manifiesto de manera palpable si comparamos un sencillo indicador de variabilidad del precio en los distintos mercados. La Tabla 2 recoge la desviación típica de las series de precio del trigo sin tendencia, agrupadas por distintos períodos a lo largo de la Edad Moderna. Los resultados subrayan la situación verdaderamente privilegiada de Barcelona y de Valencia, donde la intensidad de las fluctuaciones se sitúa en torno a la mitad de la que caracteriza los demás mercados ${ }^{19}$. En realidad, se pueden distinguir cuatro tipos de mercado diferente. Por un lado están los citados mercados costeros, seguidos a cierta distancia por el almudí de Pamplona. La intensidad de las fluctuaciones era mayor en Andalucía, y algo menor en los tres mercados de la Meseta ${ }^{20}$. La volatilidad de precios es muy superior (entre 2,5 y 5 veces) a la que se da, por ejemplo, en Madrid hacia finales del siglo xIx, aunque esta diferencia es menor si basamos la comparación en el período $1750-1800^{21}$.

Estas disparidades se pueden ver desde otra perspectiva. Aunque es difícil establecer arbitrariamente el umbral mínimo de lo que se podría denominar como una importante crisis de subsistencias, si consideramos un aumento de más del 40 por 100 sobre la media móvil subyacente de 11 años como indicador de una situación en potencia de hambruna, las disparidades de los mercados regionales de grano vuelven a presentarse.

${ }^{19}$ Muchos autores han subrayado la incidencia menor de años de crisis en los mercados principales de las zonas costeras. Véase, por ejemplo, Palop Ramos (1977, pp. 27.31) y Anes Álvarez (1969, pp. 56-61; 1970, pp. 199-213).

${ }^{20}$ La mayor volatilidad de los precios en Andalucía ha sido senalado por Antonio Domínguez Ortiz, que plantea la posibilidad de que se podría deber a un clima más extremo en dicha región (1976, pp. 406).

${ }^{21}$ La reducción en la volatilidad de los precios de grano en España entre el Antiguo Régimen y la segunda mitad del siglo XIX no es muy diferente a la de otros mercados europeos (Persson, 1999, pp. 107-108). 


\section{TABLA 2}

Variabilidad del precio del trigo en distintas plazas españolas durante la Edad Moderna

(desviación típica de series sin tendencia)

\begin{tabular}{cccccccc}
\hline Periodo & Andalucia & $\begin{array}{c}\text { Castilla } \\
\text { la Nueva }\end{array}$ & Segovia & León & Barcelona & Navarra & Valencia \\
\hline $1500-1550$ & & 0,331 & & & 0,168 & & 0,234 \\
$1550-1600$ & 0,382 & 0,272 & & & 0,152 & & 0,144 \\
$1600-1650$ & 0,357 & 0,286 & & 0,320 & 0,168 & 0,283 & 0,141 \\
$1650-1700$ & 0,384 & 0,331 & 0,349 & 0,326 & 0,297 & 0,220 & \\
$1700-1750$ & 0,305 & 0,263 & 0,254 & 0,286 & 0,116 & 0,209 & \\
$1750-1800$ & 0,223 & 0,245 & 0,242 & 0,269 & 0,123 & 0,191 & 0,112 \\
\cline { 2 - 8 } Total & 0,340 & 0,288 & 0,264 & 0,288 & 0,182 & 0,226 & 0,165 \\
\hline
\end{tabular}

NOTA: La falta de estimaciones es debida a la carencia de datos o a la existencia de un número insuficiente de casos.

Nota: Como referencia general, conviene tener presente que la variabilidad del precio del trigo en Madrid hacia finales del siglo xix está en torno al 0,075.

En Andalucía este tipo de crisis ocurre una vez cada 10,6 años, en Castilla la Nueva cada 9,8 años, en Segovia cada 14,1 años, en Navarra cada 36,8 años, en Valencia cada 38,4 años y en Barcelona cada 69 años ${ }^{22}$. Con estos datos, no es posible fijar un umbral de «crisis», «grave carestía» o «hambruna» de manera segura. No obstante, si se recuerda la importancia del trigo dentro del presupuesto familiar y el hecho de que era un producto de una demanda básicamente inelástica, un aumento en su precio de 30 ó 40 por 100 tenía que haber sido gravísimo para la economía familiar. También hubo años en la Meseta y en Andalucía en los que los precios aumentaban en más del 75 por 100 sobre sus niveles normales e incluso hubo algún año en el que se doblaban. Más grave todavía, sin embargo, serían aquellos períodos en los que se juntaban dos o más años de precios elevados, hecho relativamente infrecuente en Barcelona, Navarra y Valencia, pero bastante recurrente en la Meseta y en Andalucía.

Cabe destacar cuatro posibles razones para esta disparidad en el comportamiento de los precios regionales. Es posible, al menos en teoria, que la producción de granos en las zonas costeras sufriera oscilaciones menos

${ }^{22}$ Si optamos por el umbral de fluctuaciones mayores del 30 por 100 en un año, su incidencia es cada $5,1,7,6,7,5,11,6,21,3$ y 46 años, respectivamente. 
bruscas que en el interior debido a razones climatológicas y geográficas. Por otra parte, los mercados fuertes de la costa (Barcelona y Valencia), y en menor medida el de Pamplona, estarían mucho más cercanos a las vías del comercio internacional que podía mitigar los periodos de escasez de granos y, además, en condiciones de atraer trigo del interior de la Península ${ }^{23}$. También cabe señalar la posibilidad de que una menor dependencia del trigo en la costa fuera debido a la existencia de un régimen alimenticio más variado (con pescado, frutas, etc.), y por tanto una demanda de grano más elástica que en el interior. Finalmente, cabe la posibilidad de que los mercados de la costa se nutrían, al menos en parte, de la producción cerealera del centro de la Península, mientras que los mercados del interior tendrían poco acceso al trigo proveniente del comercio internacional o incluso - tal vez- de la producción de las zonas costeras ${ }^{24}$. Este tema volverá a centrar nuestra atención más adelante.

La Tabla 2 también indica que en todas partes se produjo un descenso notable en la variabilidad de los precios a lo largo del siglo xvII ${ }^{25}$. No hay excepción en este punto. Los mercados de trigo de Barcelona y Valencia se situaron en niveles de estabilidad desconocida en épocas anteriores, sin ningún año verdaderamente inflacionario en todo el siglo. En el caso de Barcelona, donde los datos no tienen lagunas, hay que remontar a 1677-1678 para encontrar lo que se podría denominar una crisis importante. Sin alcanzar la situación envidiable de estas plazas, los demás mercados peninsulares mostraron una importante reducción en la variabilidad de los precios del trigo. No debemos restar importancia a este proceso, a pesar de los importantes contratiempos que hubo en el interior, siendo el ejemplo más notable la gravísima crisis de $1803-1805^{26}$. Terminó teniendo enormes implicaciones tanto para la salud de la población como para la incidencia del riesgo en las economías familiares, en particular en las zonas rurales. La causa de esta reducción en la intensidad de las fluctuaciones de los

${ }^{23}$ Es sabido que Barcelona, por ejemplo, de manera habitual se abastecía de trigo proveniente de Andalucía, Sicilia, Argelia, Inglaterra, del interior de Cataluña (sobre todo de Lleida) y especialmente de Aragón. Véase, al respecto, Feliú (1992).

${ }^{24}$ Los mercados del interior, sin embargo, aun enviando trigo hacia la costa, serían menos capaces de acceder al comercio internacional de granos, salvo en el caso de Madrid. Para más sobre este tema, véase Castro (1987, pp. 267-278) y Ringrose (1983, pp. 144-154).

${ }^{25}$ Este resultado es similar al encontrado por Escrivá y Llopis al estudiar los distintos mercados de Castilla la Vieja y León durante la Edad Moderna (1987, p. 27).

${ }^{26}$ Esta crisis de subsistencias, que se hizo acompañar por una epidemia terrible de tifus y de paludismo en el interior de la Península, fue posiblemente la crisis de esta naturaleza más grave en todo el Antiguo Régimen. Véanse, al respecto, Reher (1980; 1990, pp. 151-188) y Pérez Moreda (1980, pp. 375-389). 
precios del trigo podría residir en una incipiente integración de los mercados de granos de la Península, en un aumento en la importancia del comercio internacional, en un improbable cambio climático de gran alcance, o en cambios en las técnicas de producción acompañados por un posible aumento en la producción per capita en el largo plazo.

Sea cual sea la explicación de mayor peso, estos resultados vuelven a apuntar la posible existencia de una cierta integración de los mercados de grano en la Península. Es difícil dudar que los mercados de, al menos, Barcelona y de Valencia estaban ya integrados en el mercado internacional de cereales y que este proceso de integración aumentaba a lo largo del Siglo de las Luces. Este proceso podría explicar la reducción en la volatilidad de los mercados, aunque en estos momentos no es más que una hipótesis razonable. Conviene profundizar algo más en esta cuestión.

Si miramos estas fluctuaciones de manera más atenta, se puede constatar la existencia de una sintonía nada despreciable entre las variaciones anuales de los precios sin tendencia en los distintos mercados regionales de granos, indicando así la coincidencia de años buenos y malos en muchos de ellos. Esto se desprende de un análisis por correlaciones de las series de precios en distintos lugares cuyos resultados principales se recogen en la Tabla $3^{27}$. Hemos incluido tanto las correlaciones en el mismo año como las correlaciones entre los precios en un año en una plaza y en el año siguiente en otra, permitiéndonos así comprobar la existencia de relaciones retardadas.

Los resultados son llamativos e indican que existe un evidente vínculo entre las distintas series de precios, que en una parte de los casos es simultáneo y retardado. Se comprueba asimismo, como no podía ser de otra manera, una mayor sintonía entre algunos mercados que entre otros. La compenetración mayor de precios se encuentra entre Segovia, Castilla la Nueva y, en menor medida, León, aunque también se observa una covariación elevada entre Segovia y Andalucía y Pamplona y entre Castilla la Nueva y Valencia ${ }^{28}$. Lo más notable, no obstante, es que entre todos los mercados peninsulares existe una correlación positiva en el mismo año, aunque normalmente no sea muy elevada. También dicha correlación suele ser positiva y a veces fuerte con un retardo de un año, con la excepción de los precios

${ }^{27}$ Es conveniente recordar aquí que la utilización tanto de años civiles como de años cosecha en las series originales aconseja matizar nuestra interpretación de los resultados.

${ }^{28}$ Este resultado es muy similar al hallado por Escrivá y Llopis $(1987$, p. 126) al analizar, con una metodología más sofisticada que la utilizada aquí, las fluctuaciones en los precios de distintos mercados de Castilla la Vieja y León. 


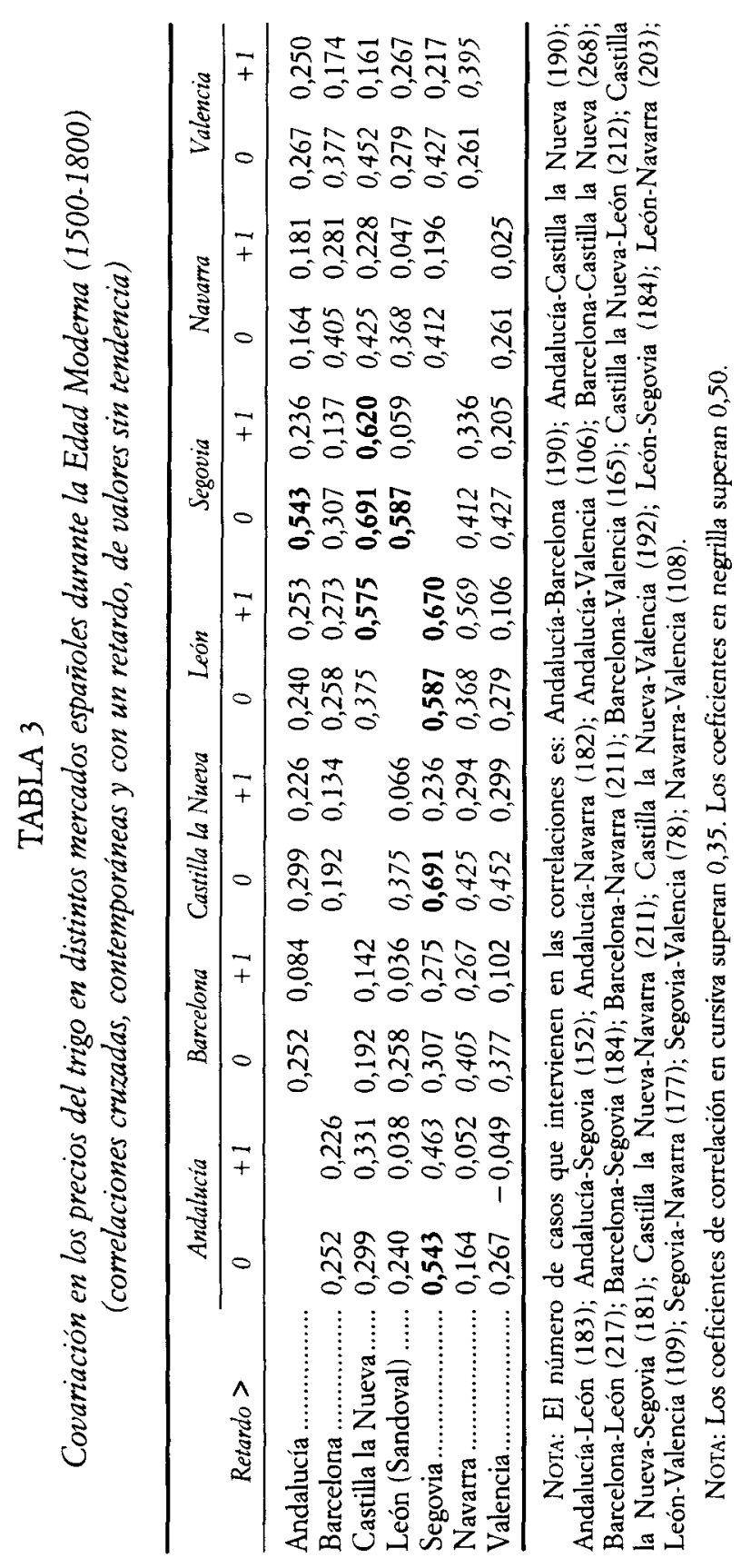


de Pamplona y de Valencia al compararse con los de Andalucía un año después. En términos generales, son los mercados del centro de la Península los que muestran unas correlaciones con otros mercados más elevadas, y los de la periferia donde dichas correlaciones son menores.

Existen dos posibles explicaciones para esta asociación estadística. Por un lado, parece haber indicios de una efectiva integración de los distintos mercados mediante lo cual el grano circulaba de uno a otro de acuerdo con los precios vigentes y la cantidad de grano sobrante. Si la integración de mercados hubiese sido mayor, las correlaciones habrían sido muy superiores y de hecho se habría llegado a la existencia de un solo mercado de grano en la Península. Evidentemente, ello no era así y por ello los vínculos puestos de manifiesto son a veces débiles. Aun así, la circulación de trigo entre los distintos mercados explicaría en parte los resultados obtenidos. Además, también explicaría las correlaciones retardadas obtenidas, ya que indicaría la posibilidad de que el trigo traspasara los confines de una región entre un año y otro. La otra explicación posible a los resultados aquí presentados se basa en la existencia de una covariación positiva entre las cosechas en distintas regiones debido a similitudes climatológicas.

\section{PRODUCCIÓN, PRECIOS E INTEGRACIÓN DE MERCADOS}

Antes de continuar con estas indagaciones acerca de la integración de los distintos mercados de cereales en la Península, es obligado examinar primero la relación existente entre producción y precios dentro de una determinada comarca o región. Esta cuestión es de vital importancia tanto si hemos de comprender de modo cabal el funcionamiento de los mercados de grano como si pretendemos comprender mejor los efectos de cara al nivel de vida de la población de las fluctuaciones en los precios de los alimentos. Las fluctuaciones en los precios tendrán implicaciones para el bienestar de las poblaciones que acuden al mercado para la compra de los alimentos (poblaciones urbanas por excelencia), aunque no necesariamente para aquellos productores de alimentos, a menos que dichos precios reflejen fielmente las fluctuaciones de las cosechas. De lo contrario, podría fácilmente darse una situación en la que el productor de alimentos saliese ganando en períodos de carestía, ya que estaría en condiciones de vender su propio producto a mayor precio. Por otro lado, podemos suponer que el precio de los alimentos en un mercado determinado debería reflejar las cosechas en aquellas zonas suministradoras de productos del campo. 
Es decir, cuanto menos integrado esté un mercado de cereales con otros mercados, más debería depender de la producción local para sus necesidades, siendo lo contrario con mercados verdaderamente integrados.

Afortunadamente, en la España del Antiguo Régimen estamos en condiciones de comprobar el grado de dependencia de algunos mercados de cereales de la producción de su entorno. Para empezar este análisis se han elegido los datos correspondientes a Castilla la Nueva, que forman no sólo la serie ininterrumpida más larga disponible, sino también la de mayor calidad, al menos hasta 1699. En este análisis se utilizará un modelo que incorpora retardos, ya que tanto por la naturaleza de la forma en la que se recogían datos de precios y de producción, como por posibles efectos institucionales e incluso personales tendentes a amortiguar las implicaciones de cosechas fluctuantes, es muy posible que los efectos de una cosecha determinada se retrasasen en el tiempo.

Los resultados de esta primera aproximación son muy elocuentes, ya que ponen de manifiesto no sólo la relación simultánea prevista, sino un efecto retardado muy importante (Tabla 4). En Castilla un aumento en la cosecha de un 100 por 100 procuraba la baja del precio del cereal en un 75 por 100 ese año. Además, la misma cosecha reducía los precios en un 67 por 100 el año siguiente y en un 47 por $100 \mathrm{el}$ año después, siempre controlando por los efectos de las otras variables independientes.

\section{TABLA 4}

Producción de cereales y precio del trigo en Castilla la Nueva

\begin{tabular}{lrcc}
\hline \multicolumn{1}{c}{ Variable independiente } & Coeficiente & Estadistica-t & Prob. \\
\hline C .......................................... & 3,0927 & 12,19 & 0,000 \\
Castilla la Nueva-Diezmo ......... & $-0,7493$ & $-9,127$ & 0,000 \\
Castilla la Nueva-Diezmo $(-1) .$. & $-0,6701$ & $-7,863$ & 0,000 \\
Castilla la Nueva-Diezmo $(-2) .$. & $-0,4675$ & $-5,380$ & 0,000 \\
Castilla la Nueva-Diezmo $(-3) .$. & $-0,0942$ & $-1,114$ & 0,266 \\
Castilla la Nueva-Diezmo $(-4) .$. & $-0,1178$ & $-1,471$ & 0,143 \\
AR (1) ........................................ & 0,2919 & 4,599 & 0,000 \\
AR (2) .................................... & $-0,1356$ & $-2,128$ & 0,034 \\
\hline R-cuadrado ................................ & 0,431 & & \\
R-cuadrado (ajustado)................. & 0,415 & & \\
\hline
\end{tabular}

Nota: Variable dependiente: precio del trigo. Periodo $1545-1795$ con 251 observaciones. Variables sin tendencia. 
El efecto negativo previsto recibe una fuerte confirmación, así como su prolongación en el tiempo. Sin duda alguna, el primer determinante del precio del trigo en la submeseta sur era la bonanza o no de la cosecha de cereales en esa misma región ${ }^{29}$.

El efecto retardado reviste, asimismo, un gran interés. Debería de haber una relación estructural entre los dos indicadores, evidente en retardos 0 y 1 . La cuantía de la cosecha se conoce o bien en torno a los meses de junio o julio, o algo antes si el indicador se basa en la cosecha esperada, empezando a afectar los precios desde ese momento hasta la cosecha siguiente ${ }^{30}$. Puesto que los precios utilizados se recogen en varias fechas de un mismo año, la cosecha tenía que afectar necesariamente a precios en dos años. Una parte del primer retardo $(-1)$ y todo el segundo $(-2)$, sin embargo, son muy llamativos porque también indican la existencia de factores institucionales e incluso personales (de ahorro) que se pondrían en marcha en tiempos de carestía a fin de amortiguar de alguna manera los efectos de una cosecha fallida total o parcialmente. Estos mismos factores informarían también, al menos en parte, el hecho de que una buena parte de la varianza queda por explicar dentro del modelo propuesto. Estos resultados revindican, al menos indirectamente, algunos de los aciertos de la Monarquía, de la Iglesia y de los gobiernos locales en materia de beneficencia pública, así como la capacidad de los productores de grano para prevenir los riesgos inherentes en una producción agrícola fluctuante. Una lectura alternativa (pero tal vez complementaria) de estos resultados resaltaría el papel de una cierta integración de los mercados a la hora de amortizar y prolongar los efectos de una cosecha fallida. Con modelos paralelos para los períodos $1545-1650,1580-1720$ y $1670-1800$, se ha podido constatar una progresiva pérdida de poder explicativo del modelo ${ }^{31}$. Este resultado parece indicar que el mercado de grano de Castilla la Nueva dependía progresivamente menos de las cosechas de su propia región y se puede considerar como una prueba indirecta de un aumento en la integración de los mercados a lo largo del período bajo estudio, al menos en lo que se refiere al de la submeseta sur.

${ }^{29}$ Para una discusión interesante acerca de la relación entre la cosecha y los precios en el contexto de Inglaterra y de Francia, véase Wrigley (1987, pp. 92-130). Uno de los puntos que este y otros autores resaltan es el hecho de que la relación entre las dos variables no es lineal, efecto no recogido en los modelos aqui utilizados.

${ }^{30}$ Ello no descarta la existencia en años de escasez de acaparamiento de granos que sólo llegarian al mercado en los «meses mayores» antes de la próxima cosecha. Para abundar sobre esto, véanse Reher (1980), Anes (1970) y De Castro (1987).

${ }^{31}$ El R-cuadrado es 0,59 en el primer modelo, 0,52 en el segundo y 0,43 en el tercero. 
Aparte de la serie de producción de Castilla la Nueva, también contamos con otras dos series, una correspondiente al Oriente leonés (Sandoval) y otra al Obispado de Segovia. Ninguna de estas series tiene la magnitud o la extensión de la serie castellana, pero ofrecen un punto de comparación y contraste a los datos ya utilizados. Además, al ser series de producción de tres comarcas o regiones de la Meseta, nos van a permitir apreciar el grado en el que el grano circulaba en ella. Un simple análisis por correlaciones indica que las cosechas de las tres regiones guardaban una relación tan sólo modesta entre $\mathrm{si}^{32}$. Es importante tener presente el tamaño de la zona productora a la hora de interpretar los resultados que a continuación se presentan. Mientras la zona productora recogida en la serie decimal de Castilla la Nueva es verdaderamente amplia, la de Segovia es bastante menor y la de Sandoval, en León, corresponde a una producción tan sólo local.

De nuevo hacemos uso de los modelos de retardos distribuidos, aunque esta vez hacemos a los precios del trigo en Castilla la Nueva, Segovia y León depender de las fluctuaciones de las cosechas, contemporáneas y retardadas, tanto de sus regiones de referencia como de las otras dos regiones para las que disponemos de series de producción ${ }^{33}$. Los resultados contenidos en la Tabla 5 son elocuentes; confirman y matizan buena parte de lo que se ha venido afirmando. Demuestran, por un lado, la preponderancia de las cosechas locales en la determinación de las fluctuaciones del precio de trigo en los distintos mercados regionales. Evidencian, asimismo, la importancia de la producción en otras regiones aunque esta producción no influya de modo igual en los distintos mercados.

En Castilla la Nueva, el precio del grano está determinado por las cosechas del Arzobispado de Toledo y, en menor medida, por la del Obispado de Segovia, siendo inapreciable la influencia de la producción leonesa. El mercado de Segovia se muestra susceptible a la producción en toda la Meseta, aunque se nutre principalmente de la producción de la submeseta sur y de sus propias tierras. Esta preponderancia de Castilla la Nueva parece ser más producto de la amplitud de la zona productora y de la capacidad del mercado segoviano de atraer grano desde el sur, que de una falta

${ }^{32}$ El coeficiente de correlación de las series sin tendencia entre Castilla la Nueva y León es de 0,41, entre Castilla la Nueva y Segovia es de 0,30 y entre León y Segovia es de 0,27 .

"A fin de reducir en la medida de lo posible el número de variables independientes dentro del modelo, sólo se han utilizado dos retardos para la región donde esté el mercado de granos y uno sólo en las demás. 


\section{TABLA 5}

Producción de cereales en distintas regiones y precios locales del trigo

\begin{tabular}{|c|c|c|c|c|c|}
\hline \multicolumn{2}{|c|}{ Castilla la Nueva } & \multicolumn{2}{|c|}{ León (Sandoval) } & \multicolumn{2}{|c|}{ Castilla la Vieja (Segovia) } \\
\hline $\begin{array}{c}\text { Variable } \\
\text { independiente }\end{array}$ & Coeficiente & $\begin{array}{c}\text { Variable } \\
\text { independiente }\end{array}$ & Coeficiente & $\begin{array}{c}\text { Variable } \\
\text { independiente }\end{array}$ & Coeficiente \\
\hline $\begin{array}{l}\text { Cast. la Nueva ......... } \\
\text { Cast. la Nueva }(-1) \\
\text { Cast. la Nueva }(-2) \\
\text { León... } \\
\text { León }(-1) \\
\text { Segovia. } \\
\text { Segovia }(-1) \\
\text { AR (1) } \\
\text { AR (2) }\end{array}$ & $\begin{array}{l}3,122^{* * *} \\
-0,783^{* * *} \\
-0,751^{* * *} \\
-0,380^{* *} \\
-0,050 \\
0,130 \\
-0,185^{*} \\
-0,108 \\
0,344^{* * *} \\
-0,137\end{array}$ & 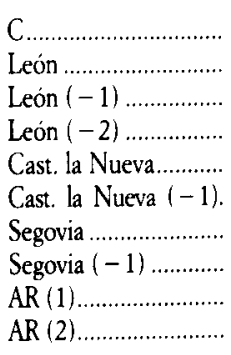 & $\begin{array}{l}2,198^{* * * *} \\
-0,284^{* * *} \\
-0,229^{*} \\
0,034^{*} \\
-0,109 \\
-0,162 \\
-0,250^{* * *} \\
-0,204^{* *} \\
0,729^{* * *} \\
-0,387^{* * *}\end{array}$ & 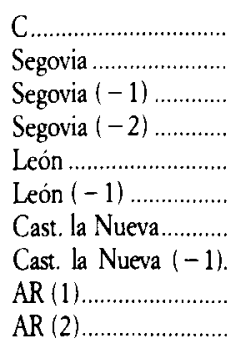 & $\begin{array}{l}2,442^{* * *} \\
-0,224^{* *} \\
-0,218^{*} \\
-0,044 \\
-0,128^{*} \\
-0,045 \\
-0,418^{* * *} \\
-0,375^{* * *} \\
0,884^{* * *} \\
0,533^{* * *}\end{array}$ \\
\hline $\begin{array}{l}\text { R-cuadrado } \\
\text { R-cuadrado (ajust.)......... } \\
\text { Período (núm. obs.)... }\end{array}$ & $\begin{array}{c}0,51 \\
0,48 \\
1579 \cdot 1745 \\
(167)\end{array}$ & $\begin{array}{l}\text { R-cuadrado............ } \\
\text { R-cuadrado (ajust.).... } \\
\text { Periodo (núm. obs.).. }\end{array}$ & $\begin{array}{c}0,61 \\
0,59 \\
1591-1745 \\
(155)\end{array}$ & $\begin{array}{l}\text { R-cuadrado .................. } \\
\text { R-cuadrado (ajust.) .... } \\
\text { Período (núm. obs.).. }\end{array}$ & $\begin{array}{c}0,70 \\
0,68 \\
1622-1745 \\
(124)\end{array}$ \\
\hline
\end{tabular}

Nota: Variable independiente: producción de cereales (diezmo) en distintas regiones; variable dependiente: precio del trigo en distintas regiones. Variables sin tendencia.

Nivel de significación: ${ }^{* * *}=<0,001 ; * *=<0,01 ;^{*}=<0,10$.

de integración con las zonas productoras leonesas. A Sandoval, en cambio, no parece llegarle el grano manchego, aunque la producción segoviana tiene un gran peso en los precios locales.

Estos resultados ponen de manifiesto la existencia de una circulación del grano de diferentes zonas productoras de la Meseta entre los mercados de la región. Podemos apreciar un mercado segoviano abierto a todas las zonas aquí recogidas, y también un mercado manchego y otro leonés menos conectados entre sí. Ello se explica en buena medida por la potencia de la zona productora, así como por la del mercado en sí a la hora de atraer grano de fuera. El mercado de Segovia era el más potente por la elevada demanda de grano que tenía, y la producción manchega era la más voluminosa, mientras la zona de Sandoval ni tenía fuerza de atracción ni tampoco generaba una gran producción. Es incuestionable que en la Meseta existía una integración considerable de los distintos mercados de granos, y que el grado de apertura al exterior y la dirección que ésta tomaba dependía de la fuerza de la oferta y de la demanda y, claro está, de la distancia. 
La falta de datos adecuados nos impide entrar en la posible integración de producción de, digamos, la Meseta y la venta de grano en los mercados de la periferia. En la Tabla 3 se pudo apreciar una covariación apreciable de los precios de grano, aunque normalmente con niveles inferiores a los existentes en la Meseta. Por ello, los indicios de cierta integración entre Meseta y periferia han de quedar más como una sugerencia que como un hecho probado. En todo caso, aun constatando su existencia, es evidente que sería un grado de integración muy inferior que la que hemos podido observar en ambas Castillas y León.

\section{EVALUACIÓN DE LOS RESULTADOS}

A lo largo de este escrito hemos podido comprobar varios aspectos del funcionamiento de los mercados de trigo en la Península. Se ha puesto de manifiesto la gran variabilidad en el precio del trigo, alimento básico de la población. Esta volatilidad, que a veces ha llegado a ser más que el doble en los mercados del interior que en los de la costa, tendió a disminuir de manera significativa a lo largo del siglo xvn. A esas alturas, en algunas regiones costeras (Barcelona, Valencia) habían desaparecido prácticamente las grandes crisis de subsistencias, aunque no en la cuenca del Guadalquivir, al menos antes de 1750. En las zonas del interior, sin embargo, a pesar de la mejoría, seguía habiendo fuertes fluctuaciones en el precio del grano. También se ha comprobado la existencia de una sintonía entre los precios del trigo de distintas plazas españolas que se ha atribuido a un grado de integración modesta pero no despreciable de los mercados. Al comprobar específicamente el efecto de las cosechas sobre el precio del trigo, se ha podido ver un efecto fuerte y dilatado en el tiempo, así como la importancia que tenía la producción en algunas regiones sobre los precios en otras. Estos resultados permiten comprender mejor las dinámicas de los mercados de granos, los determinantes de las oscilaciones en los niveles de vida de la población y el papel que las instituciones desempeñaban de cara al bienestar de la población. Algunos de ellos son muy novedosos y otros confirman lo que se venía sospechando. Todos, sin embargo, tienen implicaciones sustanciales de cara al funcionamiento de las sociedades peninsulares durante la Edad Moderna.

Este escrito se ha centrado en las oscilaciones a corto plazo en los precios y las cosechas. Las fluctuaciones anuales de los precios se pueden atribuir tanto a las cosechas como a los elevados precios del transporte 
y almacenaje de granos que limitaban cualquier previsible integración de los mercados (Persson, 1999). Tenían importantes implicaciones para la población. Existe una amplia literatura, que abarca tanto países europeos como países en vías de desarrollo en épocas no lejanas, que testimonia la clara y significativa relación entre los cambios a corto plazo en los precios (o de la situación económica en general) y el comportamiento demográfico. En esta literatura se ha demostrado cómo los años de carestía deprimían la fecundidad - sobre todo mediante la reducción en la incidencia de concepciones-y la nupcialidad y aumentaban la mortalidad ${ }^{34}$. En años extremos podía haber hambrunas, con personas muriéndose de hambre en las calles, al menos a juicio de los contemporáneos. Además, los períodos de fuerte inflación iban acompañados a menudo por epidemias y por aumentos generalizados de la mortalidad ${ }^{35}$.

La inestabilidad de precios también tenía efectos a medio y largo plazo sobre la sociedad, ya que impedía el ahorro y la especialización del trabajo agricola y, sobre todo, obligaba a dedicar un porcentaje elevado de la población al cultivo de cereales, producto —en opinión de todos- imprescindible para la supervivencia y bienestar de la gente. En todos los países europeos conseguir una estabilidad en los precios de los alimentos básicos era un paso previo imprescindible para la llegada de una verdadera modernización económica con todo lo que implicaba. Este paso se lograría mediante la integración de los mercados, parte esencial para cualquier transformación de la sociedad. En este sentido cabe destacar la gran ventaja que tenía el norte de Europa sobre el sur del continente y la que tenía el litoral de España sobre el interior, hecho que incuestionablemente contribuyó decisivamente a un despegue económico anterior en aquellas zonas $^{36}$.

En todo caso, también es cierto que se detectan signos bastante claros de esa integración de los mercados durante el siglo xviI que tanto buscaban los reformadores ilustrados ${ }^{37}$. De hecho, siempre hubo indicios de integración, aunque durante buena parte del Antiguo Régimen éstos eran débiles. Durante el siglo xvII, sin embargo, estos indicios aumentaron considerablemente. Aunque lejos de ser un mercado perfectamente integrado,

${ }^{34}$ Para el caso de España, véanse Reher (1988), Pérez Moreda (1988) y Reher y Sanz Gimeno (2000).

${ }^{35}$ Véase, por ejemplo, Livi Bacci (1988).

${ }^{36}$ Véase, por ejemplo, Reher y Ortega Osona (2000).

${ }^{37}$ En la misma línea de Escrivá y Llopis (1987, pp. 126-127) para los mercados de la submeseta septentrional. 
afirmar que no había ningún tipo de integración sería una falsedad histórica. A lo largo de este estudio hemos aportado varias pruebas que subrayan que la sintonía de precios en distintas regiones no obedecía más que muy parcialmente a una covariación positiva en las cosechas e indicaba que efectivamente las cosechas de unas regiones terminaban vendiéndose en los mercados de otras, afectando así los precios en zonas a veces bastante lejanas ${ }^{38}$.

Había dos agentes principales en este tráfico de granos. Por un lado, estaban los comerciantes de grano que se proveían principalmente del producto del diezmo eclesiástico, a menudo tras las pujas de rigor, o del producto de los grandes propietarios, vendiéndolo donde mejor estaba el precio. Habitualmente se ha venido pensando que los lugares de venta del producto del diezmo se encontrarían localizados dentro de las mismas comarcas productoras. Ante las pruebas presentadas aquí, parece probable que a menudo estos granos circulaban bastante más allá de sus zonas de origen, en busca de los mejores precios y de las mayores ganancias para los vendedores. En todo caso, cabe subrayar que el diezmo fue siempre un instrumento que facilitaba la circulación de granos durante el Antiguo Régimen, tanto en ámbitos locales como hacia las ciudades, o con destino a otras regiones.

El otro gran agente de circulación eran los compradores de granos en instituciones donde la demanda de alimento era elevada o donde la institución era poderosa. En realidad, una buena parte de las fuentes de precios que tenemos a nuestra disposición provienen de instituciones de estas características, que incluyen los pósitos y los almudíes de ciudades como Segovia o Pamplona, mercados municipales de granos o importantes conventos, hospitales y catedrales. Estas instituciones tenian capacidad para acudir a la compra de granos en lugares a veces muy lejanos, y por lo tanto contribuían poderosamente a la integración que hemos comprobado ${ }^{39}$. Cuanto más importante el mercado, mayor su capacidad de conseguir trigo en otras regiones o en el extranjero y, como hemos visto en este trabajo, esta capacidad influía significativamente en las fluctuaciones de los precios del grano. De hecho, las ciudades en sí, y en particular los grandes centros urbanos como Madrid, Valencia, Sevilla o Barcelona, al

${ }^{38}$ Estos resultados reflejan, pero desde una óptica distinta, los resultados de numerosos estudios monográficos de distintos mercados.

${ }^{39}$ Existen múltiples ejemplos de estas prácticas de compra de granos en lugares lejanos por parte de las grandes instituciones urbanas. Para un repaso general a esta problemática, véase Reher (1990, pp. 154-163). Véase, también, de Castro (1987) o Anes Álvarez (1968). 
ser centros muy importantes de consumo de granos, tenían un efecto integrador de cara a la circulación de cereales provenientes a veces de regiones muy lejanas.

Es evidente que este tipo de integración interregional no se producía de la misma manera en los mercados locales, mucho menos potentes y con menor capacidad para atraer grano de otras regiones. Estos mercados, sin embargo, sin duda no serían estrictamente locales tampoco, ya que se llegaría a vender trigo producido en comarcas a veces relativamente lejanas, aunque normalmente dentro de la misma región. De nuevo, los agentes principales de esta dinámica serían los comerciantes de granos provenientes sobre todo de los diezmos de la Iglesia o de grandes productores de granos, siendo éstos importantes sobre todo en zonas donde predominaba la gran propiedad. En todo caso, estos mercados locales, limitados por su falta de potencia, tendrían un acceso escaso a la producción de cereales de otras regiones y casi nula a las redes comerciales internacionales ${ }^{40}$.

En este sentido, al menos en principio, parecería plausible que, dentro de una misma región, los precios de cereales sufriesen oscilaciones mucho más pronunciadas en los pequeños mercados locales que en los grandes mercados centrales. No obstante, a esta observación habría que oponer la existencia de una superior demanda de alimentos entre poblaciones no productoras en las grandes ciudades que tendería a neutralizar el efecto previsto. Por otra parte, en el funcionamiento de los mercados intervenían otros factores a menudo ajenos a la estricta oferta y demanda de trigo que podían condicionar fuertemente la relación entre ambos. Principales entre ellos eran los especuladores que a menudo controlaban el comercio de granos, procurando retrasar la entrada de cereales en los mercados hasta que hubiese alcanzado su precio máximo posible. Sus contemporáneos les llamaban «acaparadores» y es incuestionable que intentaban, siempre que fuese posible, aumentar los precios de grano en los años de escasez, siempre que la demanda existente lo permitiera. Esta realidad, que no desaparecería hasta la completa integración de los mercados, sería un factor muy distorsionador en el funcionamiento de los mercados, y estaría presente independientemente - al menos en principio- de la importancia del mercado en sí.

Uno de los resultados más notables de este trabajo permite comprobar el papel relevante de las instituciones como amortiguadores de la intensidad

${ }^{40}$ En tiempos de crisis, las grandes ciudades (y los grandes mercados) se aseguraban el suministro del cereales a menudo a expensas de las localidades más pequeñas. 
de las fluctuaciones de las cosechas a lo largo del Antiguo Régimen en España. Este resultado, no esperado en principio, tiene implicaciones innovadoras para nuestra forma habitual de comprender el funcionamiento de la sociedad española de la época. Ya se ha descrito el papel de instituciones como la Iglesia y los gobiernos municipales de cara a la circulación de granos que, dada la relativa inutilidad de la tasa, era la única manera de asegurar su justiprecio. Aunque no siempre colmada con éxito, se ha visto en nuestro análisis cómo la intervención institucional tuvo una indudable influencia en el precio final de trigo, puesto de manifiesto sobre todo en la comprobación de que una fluctuación en la cosecha durante un año tenía no sólo el efecto simultáneo esperado $(0,-1)$, sino otro retardado que duraba al menos dos y tal vez más años. Esta dinámica se explica en parte por el hecho de que las instituciones servían como colchón que amortiguaban el efecto inicial de la cosecha, distribuyéndolo a lo largo de varios años. Los pósitos, las instituciones de beneficencia, las limosnas de la Iglesia, los préstamos de los párrocos a los productores de granos, la renuncia por parte de la Corona a las tercias reales, actuarían como complemento a la llegada de grano proveniente de otras zonas para distribuir los efectos nefastos de una cosecha fallida sobre un período relativamente prolongado. Estos factores, junto con la iniciativa individual destinada a conjugar en la medida de lo posible los efectos derivados del riesgo, formarían el colchón protector de la población, no siempre del todo eficaz, ante las incertidumbres de la producción agrícola. A pesar de ello, sin embargo, también cabe afirmar que en el largo plazo los esfuerzos de las instituciones públicas por controlar el comercio de granos terminaban retardando una verdadera integración de los mercados que sólo se lograría mediante el libre juego de fuerzas del mercado, como bien entendian algunos de los reformadores ilustrados ${ }^{41}$.

\section{LA CULMINACIÓN DEL PROCESO DE INTEGRACIÓN: ALGUNOS BREVES APUNTES}

Los indicios de integración de los mercados de cereales puestos de manifiesto en este trabajo no deberían hacernos olvidar que se trata de una integración modesta. España, con excepción de su litoral, ocupaba una situación de relativa desventaja si la comparamos con otros países

\footnotetext{
${ }^{41}$ Véase, al respecto, Persson (1999, pp. 86-90).
} 
europeos, sobre todo del norte del continente. En Inglaterra, por ejemplo, prácticamente no había fluctuaciones severas en los precios a partir de principios del siglo xvil, con el resultado de, por ejemplo, una reducción muy considerable en las oscilaciones de la mortalidad y probablemente también en los niveles generales de mortalidad ${ }^{42}$. La España del interior no gozaría de este tipo de situación hasta la segunda mitad del siglo XIX e incluso más tarde. Es más, los avances en muchas regiones durante el siglo Xvill se verían truncados durante el comienzo estremecedor del siglo XTX, en muchos casos los peores años de toda la era preindustrial. A pesar de la importancia de las instituciones a lo largo del Antiguo Régimen, no existiría un verdadero mercado nacional de cereales hasta tanto no se hubiesen eliminado los obstáculos legales - y sobre todo estructurales- a la producción y al comercio de granos. La supresión de la tasa de granos en 1766 fue un intento - aparentemente fallido, al menos en parte- de hacer precisamente esto. La efectiva liberalización, sin embargo, no se lograría hasta después del final del Antiguo Régimen en España.

Es indudable que la creación de un verdadero mercado nacional era un paso previo imprescindible para que se produjera la modernización económica y demográfica en España. Hace bastante años, Daniel Peña y Nicolás Sánchez-Albornoz (1983) pusieron de manifiesto la existencia de unas transformaciones graduales, a menudo débiles, hacia una mayor integración de los mercados de cereales durante la segunda mitad del siglo XIX en España ${ }^{43}$. En tiempos recientes, este tema ha atraído la atención de varios autores cuyos trabajos nos están permitiendo ir profundizando en una cuestión de importancia crucial ${ }^{44}$. Es más, en la actualidad cabe afirmar que se está generando un verdadero debate sobre el tema. A pesar de estas iniciativas, no obstante, seguimos conociendo menos de lo que sería de desear el calendario y la extensión de este proceso tan importante.

Ello se debe, en buena parte, a la falta de datos adecuados que nos permitan aproximarnos a la evolución en el medio y largo plazo de los mercados regionales, sobre todo a lo largo del conjunto del siglo XIX. La única serie de precios de grano (pan) que abarca todo el período es la correspondiente a Castilla la Nueva y sobre todo a Madrid (a partir de

${ }^{42}$ Sobre este tema, véanse Reher y Ortega Osona (2000, pp. 202-204), Wrigley y Schofield (1981, pp. 373-377, 466-480).

${ }^{43}$ Véase Peña y Nicolás Sánchez-Albornoz (1983, en especial, pp. 115-117). Véanse, también, otros trabajos de Sánchez-Albornoz aquí citados.

${ }^{44}$ Véanse, también, trabajos recientes como los de Hoyo Aparicio (1999), Martínez Vara y Guigó (1999) o Barquín Gil $(1997,1999)$. 
1825). A pesar de sus numerosos problemas, utilizada con buen criterio, esta serie puede aclarar algunos aspectos del proceso de integración de mercados ocurrido en España a lo largo del siglo Xx ${ }^{45}$. La Figura 1 contiene una estimación de la variabilidad del precio de grano en esta zona de España desde principios del siglo Xvi hasta $1935^{46}$. Su lectura es clara, aunque a primera vista los resultados puedan parecer sorprendentes. Se puede apreciar la progresiva reducción en la variabilidad del precio del trigo a lo largo del siglo XvI, proceso ya señalado en este escrito y que parece afectar a varias regiones de la Península (ver Tabla 2). El tercer

\section{FIGURA 1}

\section{Volatilidad del precio del grano (pan) en Castilla la Nueva/Madrid}

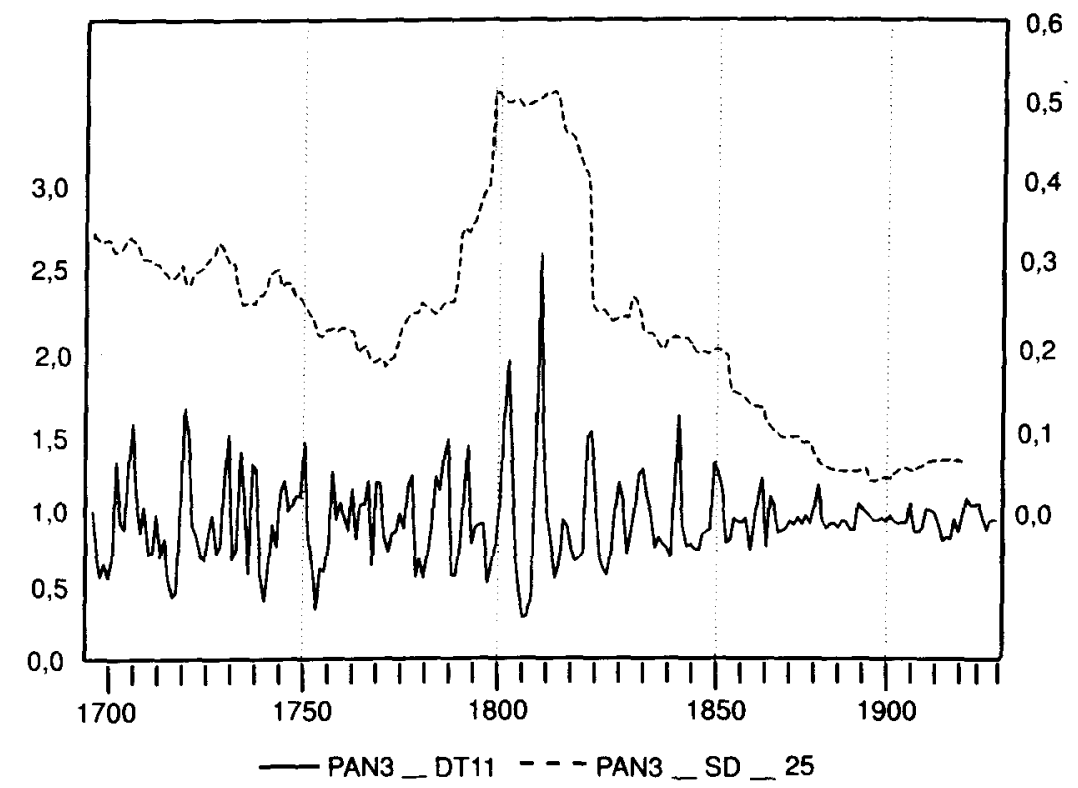

${ }^{4}$ Una de las principales debilidades de la serie es el hecho de que proviene de varias fuentes diferentes y no siempre se refiere al mismo lugar. Para una descripción detallada de la misma, véase Reher y Ballesteros (1993b). La citada serie forma parte de la serie general de precios presentados por estos mismos autores (1993a).

to En el panel de abajo figura la serie una vez quitada su tendencia, y en el de arriba se encuentra la desviación típica de dicha serie para períodos de 25 años, con la ventana de estimación corrida cada vez en un año. Es decir, se trata de una media móvil de 25 años de la desviación típica de 25 años de la serie original. 
cuarto del siglo marca el período de menor volatilidad de todo el Antiguo Régimen en Castilla, con un descenso de más del 25 por 100 con respecto a los niveles vigentes a principios del siglo xvII. A partir de ese momento se invierte la tendencia anterior $y$, hacia finales del siglo, la variabilidad se dispara gracias a la gran crisis de 1803-1805 y de los años de la guerra $(1810-12)^{47}$. Una vez pasados los años de crisis, la volatilidad del precio del pan cae drásticamente, aunque los logros del siglo XviII no se superan hasta mediados del siglo. Durante la segunda mitad del XIX se acelera esta tendencia, de tal forma que, a partir de 1880, el precio del pan en Madrid es prácticamente constante, sin apenas fluctuaciones. Después se produce un leve aumento en la variabilidad del precio, siempre dentro de unos márgenes bastante reducidos.

Por lo que se refiere al siglo XIX, una vez concluida la contienda contra Francia, estos resultados no difieren sustancialmente de los encontrados por otros autores, con otros enfoques metodológicos, en años recientes ${ }^{48}$. La originalidad de esta serie consiste en que permite yuxtaponer los logros del último siglo del Antiguo Régimen junto con los del siglo XIX. A tenor de estos resultados, el siglo xvil parece haber tenido un balance francamente positivo en este terreno, sobre todo antes de 1780 . Luego llegaron los contratiempos de principios del siglo XIX que eran extraordinariamente severos pero en modo alguno duraderos, y que fueron seguidos por un siglo de gran dinamismo en este terreno. De esta forma, pues, el proceso de integración del mercado de granos parecería arrancar durante el siglo XVII, acelerándose significativamente a partir del segundo cuarto del siglo XIX y culminándose durante los décadas finales de dicho siglo. Parecería ser, pues, un proceso de dos siglos, no de uno.

Las mejoras del siglo xviII no serían producto de cambios sociales profundos, ya que la Ilustración avanzó tan sólo tímidamente en este terreno. No obstante, se produjeron intentos por liberalizar el comercio de granos, siempre dentro de las estructuras tradicionales de la sociedad, junto con algunas obras estructurales que podrían haber tenido incidencia ${ }^{49}$. A tenor

47 De haber eliminado estos dos periodos, la fase final del Antiguo Régimen en España hubiese sido un período de aumento moderado en la volatilidad de los precios.

¿8 Por ejemplo, Martínez Vara y Guigó (1999), Barquín Gil (1997), Garcia Sanz (1985, pp. 87-98) y Garrabou y Sanz (1985, pp. 13-67) han hecho hincapié en la importancia que tenía el segundo tercio del siglo. Sus resultados parecen concordar bien con los hallados por Peña y Sánchez-Albornoz (1983). No obstante, la falta de repunte fuerte en la volatilidad de los precios madrileños durante la segunda mitad del siglo que hemos constatado aquí sí que parece entrar en contradicción con lo afirmado por Barquín Gil (1997, pp. 21-26).

${ }_{49}$ Para más sobre este tipo de reforma en Europa durante los siglos XVIII y XIX, véase Persson (1999, pp. 131-155, en especial pp. 136-143). 
del aumento considerable de la población a lo largo de la centuria, parece bastante probable que aumentase la producción del trigo gracias sobre todo a la extensión del cultivo ${ }^{50}$, aunque también hay indicios de que hacia 1780 se estaba entrando en una dinámica clásicamente maltusiana o ricardiana ${ }^{51}$. Cabe destacar, asimismo, la activa intervención de las instituciones, tanto locales como nacionales, a la hora de garantizar el abasto del trigo ${ }^{52}$. En todo caso, con los logros alcanzados en el tercer cuarto del siglo XVIII parecen haber tocado una especie de techo en esta materia dentro de una sociedad sin profundos cambios políticos y sociales y bajo una fuerte presión demográfica. De hecho, ya en las dos décadas finales del siglo -antes de los años de gran crisis de principios del siglo XIXhay indicios de un aumento apreciable en la variabilidad del precio del trigo en los mercados castellanos.

En el siglo XIX la historia es bastante diferente, y los logros son muy superiores a los del siglo anterior. Todo parece indicar que se produjo un aumento notable en la producción del trigo apoyado, en buena medida, en las políticas liberalizadoras en torno a la propiedad que se habían ido imponiendo desde la última parte del siglo xvIII ${ }^{53}$. Las más visibles de entre ellas - pero no las únicas - serían las medidas desamortizadoras, tanto durante el régimen de Carlos IV como en el de Isabel II ${ }^{54}$. Algunos autores han señalado un progresivo abaratamiento de los costes de transporte como un factor adicional, complementario, que facilitaría la circulación del trigo entre diversos mercados (Barquín Gil, 1997). Dentro de este marco explicativo, la llegada del ferrocarril no parecería ser un factor de importancia, ya que, cuando por fin llegó a ser una red efectiva, la variabilidad en el precio del pan era ya muy reducida. Cabe la posibilidad, por otra parte, de que el ferrocarril contribuyera más a la diversificación del régimen alimenticio de la población que a una reducción en sí en las fluctuaciones de los precios. Esto mismo, sin embargo, sería un elemento

${ }^{50}$ En muchas de las series decimales publicadas por Gonzalo Anes (1970) - pero no en todas - se puede apreciar un aumento notable en su cuantía a lo largo del siglo xv山, sobre todo durante su segunda mitad.

51 Véase, al respecto, Simpson (1997, pp. 45-49, 99-105).

52 Para este tema, véase Castro (1987, pp. 58-114).

53 Muchos autores han señalado la existencia de aumentos en la producción durante buena parte del siglo xIX. Véanse, por ejemplo, Llopis Agelán (1985, pp. 129-150), Simpson (1997, pp. 49.57), Hoyo Aparicio (1999, pp. 284-286), Tortella Casares (1994, pp. 51.55) y Barquín Gil (1997, pp. 26-30).

54 Por ejemplo, véanse, al respecto y desde diversos ángulos, los trabajos de Concepción de Castro (1987, pp. 297-305), Richard Herr (1989, pp. 712-754), Piero Tedde (1994), Simpson (1997, pp. 104-109) o García Sanz (1985, pp. 17-74). 
importante de cara al mercado, ya que, al reducirse la dependencia del pan, aumentaría la elasticidad de su demanda y disminuiría su importancia de cara al bienestar de la gente. En todo caso, es difícil no enfatizar más el espíritu de las reformas liberales — donde se primaba al individuo, su iniciativa, su afán de lucro, su propiedad de la tierra- que las mejoras estructurales como factor de fondo que informaba todo este proceso.

Aún queda mucho que hacer en torno a este tema, explorando con atención la situación de la primera mitad del siglo XIX o desarrollando los análisis que arrancan desde el principios de dicho siglo -e incluso antes- - y que se extienden hasta bien entrado en el siglo Xx. Además, una verdadera integración de los mercados implicaba, junto con una reducción en la volatilidad de los precios, la existencia de una convergencia real en los precios absolutos en distintos mercados, aspecto no comprendido en nuestro análisis. Los historiadores económicos españoles tienen ante sí el reto de reconstruir la dinámica de este proceso con las series de precios y producción precisas para seguirlo con el detalle que merece. En todo caso, a tenor de los datos aquí presentados, es evidente que la plena integración de los mercados de cereal en España, proceso esencial para la modernización económica del país, se logró a lo largo de dos siglos habitualmente considerados como negativos o poco positivos por buena parte de los historiadores de la economía española. Como mínimo, esta apreciación merecería una profunda revisión.

\section{BIBLIOGRAFIA}

Anes Álvarez, Gonzalo (1968): «Los pósitos en la España del siglo xviI», Moneda y Crédito, núm. 105, pp. 39-69.

- (1969): Economía e ilustración en la España del siglo XVIII, Madrid, Ariel.

- (1970): Las crisis agrarias en la España moderna, Madrid, Taurus.

- (1974): «Antecedentes próximos del motín contra Esquilache», Moneda y Cré. dito, núm. 128, pp. 219.224.

Anes Álvarez, Gonzalo, y Le Flem, J. P. (1965): «Las crisis del siglo xviI: producción agrícola, precios e ingresos en tierras de Segovia», Moneda y Crédito, núm. 93, pp. 3-55.

AruzCun Cela, Alejandro (1989): Series navarras de precios de cereales, 1589-1841, Madrid, «Estudios de Historia Económica» del Servicio de Estudios del Banco de España.

Ballesteros Doncel, Esmeralda (1997): «Una estimación del coste de la vida en España, 1861-1936», Revista de Historia Económica, núm. XV, 2, pp. 363-395. 
- (1999): «Retribuciones, poder adquisitivo y bienestar material de las clases populares. España y Castilla en la segunda mitad del siglo XIX», en TORRAS, J., y Yun Casalilla, B. (eds.): Consumo, condiciones de vida y comercialización. Cataluña y Castilla, siglos XVII-XIX, Valladolid, Junta de Castilla y León, pp. $229-244$.

BARQUIN GIL, Rafael (1997): «Transporte y precio del trigo en el siglo XIX: creación y reordenación de un mercado nacional», Revista de Historia Económica, vol. XV, núm. 1, pp. 17-48.

- (1999): «El precio del trigo en España (1814-1883)», Historia Agraria, núm. 17, pp. 177-217.

Bengtsson, Tommy, y Sarto, Osamu (eds.) (2000): Population and the Economy: From Hunger to Modern Economic Growth, Oxford, Oxford University Press. Bengtsson, Tommy; Sarto, Osamu; Campbell, Cameron, y Reher, David (1998): «Population and the Economy: From Hunger to Modern Economic Growth», en C. E. NúN̄Ez (ed.), Debates and Controversies. Proceedings of the Twelfth International Economic History Congress, Madrid, Fundación Ramón Areces, pp. 69-144.

CASTRO, Concepción de (1987): El pan de Madrid. El abasto de las ciudades españolas del Antiguo Régimen, Madrid, Alianza Editorial.

Domínguez OrtTz, Antonio (1973): Alteraciones andaluzas, Madrid, Narcea.

- (1976): Sociedad y Estado en el siglo Xvill español, Barcelona, Ariel.

Escriva, José Luis, y LLopIS, Enrique (1987): «La integración del mercado triguero en la Castilla la Vieja-León del Antiguo Régimen: Avance y estancamiento», Hacienda Pública, núms. 108-109, pp. 117-131.

Feliú I Montfort, Gaspar (1991): Precios y salarios en la Cataluña moderna, vol. I: Alimentos, Madrid, Servicio de Estudios del Banco de España, «Estudios de Historia Económica».

- (1992): «Una campanya de compra de blats per al pastrim barceloní a les terres de ponent», en Miscel.lania. Homenatge a Josep Lladonosa, Institut d'Estudis Ilerdencs, pp. 501-522.

Galloway, Patrick R. (1988): «Basic patterns of annual variations in fertility, nuptiality, mortality, and prices in pre-industrial Europe», Population Studies, 42, 2, pp. 275-303.

Garcia SAnZ, Ángel (1985): «Crisis de la agricultura tradicional y revolución liberal (1800-1850)», en Garcia SAnZ, A., y Garrabou, R. (eds.): Historia agraria de la España contemporánea, I, Cambio social y nuevas formas de propiedad (1800-1850), Barcelona, Crítica, pp. 7-99.

- (1999): «La evolución de la economía española en el siglo XvI», en Società Italiana di Demografia Storica, La Popolazione Italiana nel Seicento, CLUEB, pp. 455-472.

Garrabou, Ramón, y SANZ, Jesús (1985): «La agricultura española durante el siglo XIX. ¿Inmovilismo o cambio?», en GarrabOu, R., y SANZ, J. (eds.): Historia agraria de la España contemporánea, II, Expansión y crisis (1850-1900), Barcelona, Crítica, pp. 7-191.

GreEne, William H. (1997): Econometric analysis, Upper Saddle River (New Jersey): Prentice-Hall International. 
Grenier, Jean-Yves (1996): L'Économie d'Ancien Régime. Un monde de l'échange et de l'incertitude, Paris, Editions Albin Michel.

Hamilton, Earl J. (1934): American Treasure and the Price Revolution in Spain, 1501-1650, Cambridge, Harvard University Press.

- (1947): War and Prices in Spain, 1651-1800, Cambridge, Harvard University Press.

HERR, Richard (1989): Rural Change and Royal Finances in Spain at the End of the Old Regime, Berkeley, University of California Press.

HoYo Aparicio, Andrés (1999): «Gestión comercial, precios y crisis de subsistencia en Castilla, 1820-1874», en Torras, J., y YUN Casalilla, B. (eds.): Consumo, condiciones de vida y comercialización. Cataluña y Castilla, siglos XVII-XIX, Valladolid, Junta de Castilla y León, pp. 275-292.

LEE, Ronald D. (1981): «Short-term variation: Vital rates, prices and weather», en Wrigley, E. A., y Schofield, R. S., The Population History of England, 1541-1871: A Reconstruction, Cambridge (Mass.), Harvard University Press, pp. 356-401.

LÓPEZ SALAZAR, Jerónimo, y MARTíN Galán, Manuel (1981): «La producción cerealista en el Arzobispado de Toledo, 1463-1699», Cuadernos de Historia Moderna y Contemporánea, núm. 2, 1981, pp. 21-101.

Livi Bacci, Massimo (1988): Ensayo sobre la historia demográfica europea. Población y alimentación en Europa, Barcelona, Ariel.

LLOPIS AGELÁN, Enrique (1985): «Algunas consideraciones acerca de la producción agraria castellana en los últimos años del Antiguo Régimen», en GARCí SANZ, A., y GarraboU, R. (eds.): Historia agraria de la España contemporánea, I, Cambio social y nuevas formas de propiedad (1800-1850), Barcelona, Crítica, pp. 129-150.

Marcos Martí, Alberto (2000): España en los siglos XVI, XVII y XVIII. Economía y sociedad, Barcelona, Crítica.

Martín Aceña, Pablo (1992): «Los precios en Europa durante los siglos xVI y xVII: estudio comparativo», Revista de Historia Económica, vol. X, núm. 3 , pp. 359-398.

Martinez Carrión, José Miguel (1997): «Los niveles de vida del campesinado en la España contemporánea. Algunas reflexiones», Noticiario de Historia Agraria, núm. 14, pp. 23-53.

Martínez VARA, Tomás, 1997, «Una estimación del coste de la vida en Santander, 1800-1960», Revista de Historia Económica, vol. XV, núm. 1, pp. 87-124.

Martínez Vara, Tomás, y Guigo, Miguel Ángel (1999): «Fluctuaciones estacionales e integración de mercados en Santander y Castilla durante la primera mitad del siglo XIX», Studia Historica. Historia Contemporánea, núm. 17, pp. 185-209.

Palop RAmos, José Miguel (1977): Fluctuaciones de precios y abastecimiento en la Valencia del siglo XVII, Valencia, Institución Alfonso el Magnánimo.

Peña Sánchez de Rivera, Daniel, y Sánchez-Albornoz, Nicolás (1983): Dependencia dinámica entre precios agricolas. El trigo en España, 1857-1890. Un estudio empirico, Madrid, Banco de España, Servicio de Estudios, «Estudios de Historia Económica», núm. 8.

PÉrez Moreda, Vicente (1980): Las crisis de mortalidad en la España interior, siglos XVI-XIX, Madrid, Siglo XXI. 
- (1988): «Respuestas demográficas ante la coyuntura económica en la España rural del Antiguo Régimen», Boletín de la Asociación de Demografía Histórica, vol. 6, núm. 3, pp. 81-118.

PÉREz SánCHez, Guillermo (1996): Ser trabajador: vida y respuesta obrera, Valladolid, 1871-1931, Valladolid, Universidad de Valladolid.

Persson, Karl Gunnar (1999): Grain Markets in Europe, 500-1900: Integration and Deregulation, Cambridge, Cambridge University Press.

Phelps Brown, E. H., y HopkIns, Sheila V. (1956): «Seven Centuries of the Prices of Consumables, Compared with Builders' Wage Rates», Economica, vol. XXIII, núm. 92, pp. 296-314.

- (1957): «Wage-Rates and Prices: Evidence for Population Pressure in the Sixteenth-Century», Economica, vol. XXIV, núm. 96, pp. 289-306.

- (1959): «Builders' Wage-rates, Prices and Population: Some Further Evidence», Economica, vol. XXVI, núm. 101, pp. 18-36.

Ponsot, Pierre (1986): Atlas de Historia Económica de la Baja Andalucia, siglos XVI-XIX, Sevilla.

REHER, David S. (1980): «La crisis de 1804 y sus repercusiones demográficas: Cuenca (1775-1825)», Moneda y Crédito, núm. 154, septiembre, pp. 35-72.

- (1988): «Fluctuaciones económicas y comportamiento demográfico en la España urbana», Boletín de la Asociación de Demografía Histórica, vol. VI, núm. 3, pp. 51-80.

- (1990): Town and Country in Preindustrial Spain. Cuenca, 1550-1870, Cambridge, Cambridge University Press.

Reher, David S., y Ballesteros, Esmeralda (1993a): «Precios y salarios en Castilla la Nueva: La construcción de un índice de salarios reales, 1501-1991», Revista de Historia Económica, vol. XI, núm. 1, pp. 101-151.

- (1993b): «Indicadores de la dinámica económica en Madrid. Precios y salarios, 1800-1991», Serie Documentos de Trabajo, núm. 9, Instituto de Demografía (Madrid), Consejo Superior de Investigaciones Científicas.

Reher, David S., y SANZ-Gimeno, Alberto (2000): «Mortality and economic development over the course of modernization: An analysis of short-run fluctuations in Spain, 1850-1990», Population Studies, núm. 54.

Relier, David S., y Ortega Osona, José Antonio (2000): «Malthus revisited: Exploring medium-range interactions between economic and demographic forces in historic Europe», en BenGtsson, T., y SaITO, O. (eds.): Population and the Economy: From Hunger to Modern Economic Growth, Oxford, Oxford University Press, pp. 183-212.

Ringrose, David R. (1983): Madrid and the Spanish Economy, 1560-1850, Berkeley, University of California Press.

Sanchez-Albornoz, Nicolás (1963): Las crisis de subsistencias de España en el siglo XIX, Rosario, Instituto de Investigaciones Históricas.

- (1974): «Las regiones económica de España en el siglo XIX. Su determinación mediante el análisis factorial de los precios del trigo», Revista de Occidente, núm. 134 , pp. 212-227.

- (1975a): Los precios agricolas durante la segunda mitad del siglo XIX, vol. 1, Trigo y cebada, Madrid, Banco de España. 
- (1975b): Jalones en la modernización de España, Barcelona, Ariel.

Sebastián Amarila, José Antonio (1992): Agricultura y rentas monásticas en tierras de León: Santa Maria de Sandoval (1167-1835), Madrid, Universidad Complutense de Madrid, Facultad de Ciencias Económicas y Empresariales.

SERRANO GarciA, Rafael (1999): «Los salarios reales en Valladolid, 1760-1875: resultados e interrogantes», en Torras, J., y YUn Casalilla, B. (eds.): Consumo, condiciones de vida y comercialización. Cataluña y Castilla, siglos XVII-XIX, Valladolid, Junta de Castilla y León, pp. 245-274.

Simpson, James (1997): La agricultura española (1765-1965): la larga siesta, Madrid, Alianza Universidad.

TEDDE, Pedro (1994): «Cambio institucional y cambio económico en la España del siglo XIX», Revista de Historia Económica, vol. XII, núm. 3, pp. 525-539.

TORRAs, Jaume (1997): «Las condicionantes de los niveles de vida del campesinado en el Antiguo Régimen», Noticiario de Historia Agraria, núm. 14, pp. 19-24.

TORTElla CASARES, Gabriel (1994): El desarrollo de la España contemporánea. Historia económica de los siglos XIX y XX, Madrid, Alianza Universidad.

Wrigley, E. Anthony (1987): People, Cities and Wealtb: the Transformation of Traditional Society, Oxford, Basil Blackwell.

Wrigley, E. Anthony, y Schofield, Roger (1981): The Population History of England, 1541-1871. A Reconstruction, Cambridge, Harvard University Press.

Zulaica Palacios, Fernando (1994): Fluctuaciones económicas en un periodo de crisis. Precios y salarios en Aragón en la Baja Edad Media (1300-1430), Zaragoza, Institución Fernando el Católico. 